\title{
EFL Students' Judgments of English Idiom Familiarity and Transparency
}

\author{
Sameer S. Aljabri \\ The Department of English, Umm Al-Qura University, Makkah, Saudi Arabia
}

\begin{abstract}
This study investigates how L2 learners judge the familiarity and transparency of English idioms and whether these judgments would be associated with comprehension. It compares the performance of 90 undergraduate (Level 1 and Level 4) EFL students on tasks measuring idiom familiarity, transparency and comprehension. Results showed that the Level 4 students rated the idioms higher in familiarity and comprehended them with greater accuracy than Level 1 students did. However, students in the two groups performed similarly on the idiom transparency task.
\end{abstract}

Index Terms —idiom familiarity, transparency, idiom comprehension

\section{INTRODUCTION}

Teaching vocabulary was not a central goal of second language English instruction during the very active decades of the mid-twentieth century; however, this view has been challenged since the 1970s. Considerable emphasis and attention have been directed to vocabulary and vocabulary studies since that time. Multi-word expressions, including idioms, have gained more attention as well. They have been approached and investigated from different perspectives, ranging from form and idiom structure to metaphoricity and idiom meaning. Mantyla (2004) used five categories to organize the approaches linguists have used to study idioms: the structure of idioms, idiom processing, metaphoricity of idioms, idiom teaching and learning, and functions of idioms. This diversity of approaches indicates that the field has been quite active in the past several decades.

Idioms, such as pull someone's leg and shoot the breeze are figurative expressions whose meanings are not always determined by the literal definitions of their constituents. An idiom's meaning is usually different from the sum of the literal meanings of its components. For example, the literal interpretation of the idiom I was pulling his leg would be something like "something like jerking on someone's ankle". The phrase, however, means "I was teasing someone." Similarly, shooting the breeze, which means "talking with no purpose," has no relationship to the meanings of the phrase's composing parts. Idioms are common in both spoken and written language; for example, $6 \%$ to $10 \%$ of sentences in students' literature books designed for 8-14 year-old students contained an idiom (Nippold, 1991).

Idiom studies have a long tradition in the former Soviet Union and in Russia, but in the West idioms have not attracted great attention recently, although some studies were published in the 1960s and 1970s. In spite of the increased interest in idioms over the past several decades, scholars have not been able to agree on a definition of the term. Researchers agree that idioms are very difficult to characterize, since it is impossible to define them in an indisputable way. To make the matter even more complicated, one must also distinguish idioms from idiomaticity.

According to Lazar, Warr-Leeper, Nicholson \& Johnson (1989), 5\% to 20\% of classroom teachers' utterances directed to 5-14 -year-old students contain at least one idiom. This shows that it is necessary for children, adolescents and adults to be able to interpret idioms correctly.

Given the pervasiveness of these expressions, it is important that young people understand their meanings. Developmental studies of idiom understanding throughout childhood (e.g. Cacciari \& Levorato 1989; Gibbs, 1987, 1991; Nippold \& Rudzinski, 1993, Nippold \& Taylor, 1995), adolescence (e.g. Nippold \& Martin, 1989; Qualls, O'Brien, Blood, \& Hammer, 2003; Nippold, Taylor, \& Baker, 1996), and adulthood (e.g. Brasseur \& Jimenez, 1989; (Nippold \& Duthie, 2003) have shown a gradual improvement in idiom understanding that begins early in childhood and continues throughout adolescence and adulthood. Some of these studies mention that even a 5 year-old child can understand some figurative expressions (Gibbs, 1987). Other studies have proposed that idiom processing develops later. Nippold and Rudzinski (1993) and Nippold \& Taylor (1995) found that there was a positive correlation between transparency and idiom comprehension when participants were 14 and 17 years old.

Researchers agree that the accuracy of idiom comprehension increases during late childhood and adolescence and improves in adulthood. Nippold (1991) claimed that idiom acquisition is a continuous process with no specific developmental point when idioms are completely mastered. Nippold and Martin (1989) and Prinz (1983) pointed out that the ability of idiom comprehension is still incomplete when learners are 18 years old. Brasseur and Jimenez (1989) indicated that $51 \%$ of their $18-21$ year-old subjects could correctly interpret at least 13 out of 20 target idioms.

Most of these studies, as Chan and Marinellie (2008) stated, investigated individuals' understanding of idioms based on the interpretations and explanation they provide (e.g. Brasseur \& Jimenez, 1989; Nippold \& Martin, 1989; Nippold \& Rudzinski, 1993). Other studies investigated idiom understanding through the use of categories, that is, whether 
learners interpret idioms literally, idiomatically, or with the help of relevant information (e.g. Ackerman, 1982; Cacciari \& Levorato 1989; Gibbs, 1987, 1991). Their results show that young children give more literal interpretation than others of all ages, while adults' idiomatic interpretation improves as age increases. Other studies such as Nippold and Martin, (1989) found that when the process of idiom comprehension is concerned, better performance is associated with academic achievement and intelligence.

Previous developmental research has focused on various factors affecting the comprehension and the interpretation of idioms such as context, idiom familiarity and idiom transparency. Presenting idioms in supportive narrative contexts improves idiom comprehension, as compared with presenting them in isolation or in non-supportive contexts (Ackerman, 1982; Cacciari \& Levorato, 1989; Gibbs, 1991; Levorato \& Cacciari, 1995). Context facilitates interpretation of idioms since it provides the necessary semantic information the learner needs.

Familiarity and transparency are two important factors that have been used to describe characteristics of idioms. They may influence the difficulty a learner encounters in comprehending an idiom. Familiarity has been defined as how frequently an individual encounters an idiom. For example, have a soft spot, is a high-familiarity idiom which is used very often in the English language, but take a powder is a low-familiarity idiom which is used rarely (Nippold \& Taylor, 2002). Although idioms are considered a common part of figurative language, there are differences in the idioms' frequency of occurrence. The "language experience hypothesis" of figurative language development claims that development of figurative language depends on the amount of meaningful exposure one has to non-literal expressions (Ortony, Turner, \& Larson-Shapiro, 1985). This means that idioms which occur more often are probably learned earlier than less common idioms. In other words, frequency of exposure plays an important role in learning an idiom's meaning. This hypothesis "argues for a more gradual and protracted course of development that begins in early childhood, continuing through the school-age and adolescent years" (Nippold, Taylor, \& Baker, 1996, p. 445).

Transparency is particularly concerned with the relatedness between the literal and figurative meanings of an idiom. In transparent idioms, the literal and figurative meanings are closely related. In opaque idioms, the two types of meanings are unrelated. In other words, the idiomatic meaning may be more or less directly linked to the literal one. For example, in go by the book, the figurative meaning - to follow the directions exactly - is closely related to the literal meaning, whereas in keep your shirt on the figurative meaning -remain calm - is unrelated to the literal meaning -to continue wearing one's shirt. Nippold and Rudzinski (1993) proposed the "Metasemantic Hypothesis" to account for the discrepancy in difficulty between transparent and opaque idioms. Nippold and Rudzinski claim, with their hypothesis, that complex semantic units are learned through an active analysis of the words composing them. In other words, idioms are learned when one puts forth effort to infer the non-literal meaning from the literal one. So, for the learner to fully understand the meaning of an idiom, he/she has to actively analyze it. According to this view, hightransparency idioms are easier to understand than low-transparency idioms.

Idiom Transparency and Idiom Familiarity

Studies examining the role of familiarity in idiom comprehension show contradictory findings. Levorarto \& Cacciari (1992) investigated the relationship between idiom familiarity and idiom comprehension in children aged 7 and 9. One hundred fifty-two teachers judged how frequently 80 children were exposed to 85 idioms. Most and least familiar idioms were used in a forced-choice comprehension task in which children selected the best interpretation of each one. Their results show that familiarity plays a minor role in older children's idiom comprehension: it is significant with 7 year-old children, but not with 9-year-olds.

Nippold \& Rudzinski (1993) studied the effects of both familiarity and transparency in idiom explanation. They established levels of familiarity and transparency for a number of idioms based on adolescents' and adults' judgments. They also studied the development of idiom explanation in children and adolescents, using an explanation task. Results showed that performance improved gradually as the participant's age increased, that high-familiarity idioms were easier to explain than others, and that easier-to-explain idioms tended to be more transparent.

Nippold and Taylor (1995) studied the relationship of idiom transparency and idiom familiarity to idiom understanding in context, using a multiple-choice task. They found that there was a gradual improvement in idiom understanding during late childhood and adolescence. The study provides support for the language experience hypothesis and the metasemantic hypothesis.

In a cross-cultural study, Nippold, Taylor, \& Baker (1996) examined the development of idiom understanding in Australian youth and the relationship of idiom familiarity to idiom understanding in that population. They compared the performance of Australian youth to that of American youth in Nippold and Taylor's (1995) research. Fifty Australian children in the fifth grade and fifty in the eighth grade had a forced-choice task to examine their understanding of 24 different idioms. Results showed that idiom understanding is related to idiom familiarity. More common idioms were learned more easily and earlier than less common ones. Thus, idiom understanding develops in a similar manner in Australians and Americans: it improves during late childhood and early adolescence, remaining incomplete at the age of 13.

Qualls and Harris (1999), in a conceptual replication of Nippold and Taylor's 1995 study, tested language experience hypothesis by examining the effect of familiarity on idiom comprehension of African American and European American fifth graders. Results lent additional support to the language experience hypothesis, as there was a significant 
effect for moderate-low familiarity idioms, whereas high-moderate and high-low familiarity idioms did not distinguish the groups.

In a later study, Nippold, Moran, and Schwarz (2001) investigated idiom understanding and the role of idiom familiarity in conjunction with preadolescents' differences in language-based academic abilities (reading and listening comprehension). Results of an idiom comprehension task showed that idiom understanding was closely associated with students' familiarity with idioms and their skills in reading and listening comprehension. Moreover, students who scored higher in the idiom comprehension task outperformed their classmates with lower scores on all measures: idiom familiarity, reading comprehension, and listening comprehension.

The little different results in the studies seem to be due to a number of variables such as the age of the participants and the types of tasks they had. In some studies, explanations tasks which are suited for metasemantic knowledge have been used (Nippold and Rudzinski, 1993) while forced-choice tasks, which are more suited to test idiom comprehension, have been used in other studies (Levorato and Cacciari, 1992; Nippold and Taylor, 1995).

All of the aforementioned studies on English language idiom comprehension have concentrated on native speakers. There are very few studies on idiom comprehension by foreign or second language learners of English. This could be due to the lack of attention vocabulary has received as a focus for research in the past. Moreover, attention has shifted only recently from single words to multi-word expressions. Kellerman (1977) was one of the first to study non-native speakers' recognition of English idioms. Then Irujo (1986a, 1986b) studied Venezuelan students' acquisition of English idioms. Arnaud and Savignon (1997) investigated opaque idioms which had no similar equivalent in the learners' native language.

Even though idioms are an important feature in language, the effect of English idioms on second language learners has not been studied widely, and few studies focus on the way foreign or second language learners comprehend English idioms (Mantyla, 2004). Most of the existing studies dealt with the types of idioms that should be taught to learners of English, whether the mother tongue had an effect on idiom recognition, and the role of familiarity, transparency, and contextual characteristics on idiom comprehension, resulting in suggestions on how to teach idioms more effectively.

One of the few studies on characteristics of English idioms and their effects on comprehension and interpretation by native and non-native speakers was done by Mantyla (2004). In order to examine how different characteristics of idioms affected subjects' interpretations and how non-native speakers recognized English idioms, 180 Finnish university students completed a three-part questionnaire, in which the first section dealt with the acceptability of idioms, the second concerned the appropriateness of idioms in different contexts, and the third offered multiple-choice items, asking participants to choose the correct meaning for idioms. Results showed that idioms with identical equivalents in Finnish were easier for these subjects to interpret. Native speakers of English considered the meanings as more acceptable or less acceptable whereas there was some variation among the responses of non-native speakers. Non-native speakers recognized idioms much less easily than native speakers of English.

Kainulainen (2006) replicated Mantyla's study to investigate the effects of the students' backgrounds on idiom comprehension. A group of 115 Finnish third grade students in the senior year of secondary school completed a questionnaire in two sections: a background section which asked students about how much they were involved with the English language outside school, and a forced multiple-choice test of 20 English idioms presented within a brief context to how they could be used. Results showed that Finnish third-grade students comprehended idioms quite well, answering about $71 \%$ of the items correctly. Results were not in accordance with previous studies: "The degree of transparency did not significantly help the comprehension process and even though Finnish equivalents assisted understanding, the participants also considered some idioms easy that were opaque without any corresponding expressions in Finnish" (p. 83).

One of the few researchers to investigate idiom familiarity and transparency was Laval (2003). She investigated the role of contextual characteristics and linguistic conventions in the comprehension of idiomatic expressions by 6- and 9year-old French-speaking second language learners. She found that context had a substantial impact on idiom comprehension and that linguistic conventions had an effect in children aged 9 and was particularly strong in adults. She also found that the role of familiarity also affected results in the 9-year-old subjects and the adults.

In summary, Idioms are an interesting phenomenon in languages, and often lack equivalents in other languages. Thus, idioms can be very difficult for second language learners. There is clearly a need to study idioms from the point of view of second language learning, since most of the studies on English idioms have concentrated on the ways native speakers understand them. Most of the related empirical studies investigated the effects of familiarity, transparency, and context on idiom comprehension by native speakers. Very few studies have focused on idioms in foreign language learning and even fewer have considered EFL/ESL students. The present study is an attempt to shed light on English idiom comprehension by foreign language learners. The purpose of the present study is to determine how L2 learners judge the familiarity and transparency of English idioms. The study also seeks to determine whether these judgments will be associated with comprehension. It compares the performance of Level 1 and Level 4 undergraduate EFL students on tasks measuring idiom familiarity, transparency and comprehension.

\section{METHOD}

\section{Participants}


A total of 90 male students from the English Department at Umm Al-Qura University in Saudi Arabia participated in this study. Forty-five Level 1 and forty-five Level 4 undergraduate students were selected randomly. All were native speakers of Arabic and learners of English as a foreign language.

\section{Materials}

To ensure the validity of the experiment, a set of 20 English idioms was collected from published studies and various reference books on English idioms (Nippold \& Rudzinski, 1993; Nippold \& Taylor, 2002; Cambridge International Dictionary of Idioms; The Oxford Dictionary of Idioms; Essential American Idioms). Each idiom was a 4-5 word verb phrase (e.g. Keep your nose clean, Let your hair down, Bring the house down). Two English professors of translation judged these idioms as varied in familiarity. Moreover, these experts reported that 10 of the idioms were transparent and 10 were opaque.

\section{Procedure}

Testing was conducted in classrooms. The judgment tasks were identical to those ones used by Nippold and Taylor (2002). Three tasks were administered in the following order: Familiarity Judgment task, Idiom Comprehension Task, and Transparency Judgment task. The tasks were administered in this sequence for two reasons. First, the Familiarity judgment task asked the participants if they had heard or read the idioms before. If the participants completed this task after the idiom comprehension task, then their judgments would not have been accurate. Second, the transparency judgment task had to occur after the comprehension task because it presented the literal and non-literal meanings of the idioms. All testing was completed during one session of about 80 minutes. A description of each task follows.

\section{Idiom Familiarity Task}

Participants were given a booklet containing the 20 idioms. They were asked to indicate how often they had heard or read each idiom before. A 5-point scale was used in which each number was associated with a descriptive term (e.g. $3=$ a few times). Participants were asked to circle the number and the term that best expressed the number of times they had heard or read the idiom. The highest score possible for this task was 100 (20 idioms X 5 for the maximum rating). The lower the score, the greater the subject's familiarity. An example of this task appears below:

I have heard or read this idiom: Bring the house down:

$$
1=\text { many times } \quad 2=\text { several times } \quad 3=\text { a few times } \quad 4=\text { once } \quad 5=\text { never }
$$

\section{Idiom Comprehension task}

This task is similar to the one used by Nippold and Taylor (2002). It examined the participants' understanding of the 20 idioms they rated previously for familiarity. Participants were given booklets including the 20 idioms (each booklet presented the idioms in a distinct random order). Each idiom was presented in a brief context that provided support for the non-literal interpretation of the idiom. Each contextualized passage was followed by a question asking the meaning of the idiom, with four possible interpretations. Subjects were asked to select the best interpretation of the idiom. While all four options were related to the context, only one offered a correct interpretation. The highest possible score in this task was 20 points. The following is an example of an item in this task:

Jack, Michael and Jerry just finished final exams after a long semester. They have not gone out as a group for a while. Michael said, "Why don't we all get together and paint the town red tonight?". What does it mean to [paint the town red]?
a. To celebrate
b. To paint the house
c. To buy paintings
d. To avoid problems

\section{Transparency Judgment Task}

In this task, each subject was given a booklet containing the 20 idioms in a distinct random order. Each idiom was following by the literal and non-literal meanings. Participants were asked to judge how closely they believed both meanings were related, using a 3 -point scale $(1=$ closely related $2=$ somewhat related $3=$ not related $)$. Both meanings were taken from the reference books mentioned above. One idiom was presented as follows:

Turn the other cheek

Literal meaning: To turn your face to the other side

Non-literal meaning: To stay calm

The meanings are:

$1=$ closely related

$2=$ somewhat related

$3=$ not related

\section{RESULTS}

Table 1 reports the performance of Level 1 and Level 4 students on the three experimental tasks. It contains the mean raw scores, standard deviations, and the ranges obtained by the students. 
TABLE 1

MEAN SCORES, STANDARD DEVIATION, AND RANGE BY EACH GROUP

\begin{tabular}{l|l|l}
\hline \multicolumn{2}{c|}{} & Level 1 \\
\hline Familiarity Judgment Task (Maximum 100) & \\
M & 79.60 & 70.86 \\
SD & 10.86 & 13.92 \\
Range & $60-99$ & $38-94$ \\
\hline Transparency Judgment Task (Maximum 60) & \\
M & 46.02 & 46.00 \\
SD & 5.46 & 7.07 \\
Range & $34-57$ & $24-56$ \\
\hline Idiom Comprehension Task (Maximum 20) & \\
M & 6.82 & 13.77 \\
SD & 2.91 & 2.99 \\
Range & $2-16$ & $6-19$
\end{tabular}

The table shows that the Level 4 students rated the idioms higher in familiarity and comprehended them with greater accuracy than the Level 1 students did. However, performance on the idiom transparency task was close in the two groups. An Analysis of Variance (ANOVA) was conducted to analyze the data collected; results for the familiarity, transparency and comprehension tests follow.

TABLE 2

ANALYSIS OF VARIANCE (FAMILIARITY JUDGMENT TASK)

SCORE (OUT OF 100)

\begin{tabular}{|l|l|l|l|l|l|}
\hline & Sum of Squares & df & Mean Square & F & Sig. \\
\hline Between Groups & 1716.100 & 1 & 1716.100 & 11.005 & .001 \\
Within Groups & 13722.000 & 88 & 155.932 & & \\
Total & 15438.100 & 89 & & & \\
\hline
\end{tabular}

Table 2 reports an $\mathrm{F}$ of 11.005 , which with 1 and 88 degrees of freedom is statistically significant at the .000 level (P $<0.05)$. These figures indicate that the difference across the independent variable category is significant at a very low probability. Therefore, we can feel comfortable in rejecting the "Null Hypothesis" of no difference between the two groups of students. The difference between the two groups is also statistically significant for the familiarity judgment task. Eta Squared $\left(\mathrm{E}^{2}\right)$, the correlation ratio, measures the strength of the relationship between dependent variables and the independent variables. In this case, as seen in Table2, $\mathrm{E}^{2}$ is 0.11 for the Familiarity Judgment Task. This means that the difference between Level 1 and Level 4 students explains about 11 percent of the variation in scores for the familiarity judgment task. We could say that this relationship is weak but statistically significant.

TABLE 3

ANALYSIS OF VARIANCE (TRANSPARENCY JUDGMENT TASK)

\begin{tabular}{|l|l|l|l|l|l|}
\hline & SCORE (OUT OF 60) \\
\hline Between Groups & Sum of Squares & df & Mean Square & F & Sig. \\
Within Groups & .011 & 1 & .011 & .000 & .987 \\
Total & 3514.978 & 88 & 39.943 & & \\
\hline
\end{tabular}

As a result of the tiny differences between the means of Level 1 and Level 4 students for the transparency judgment task in Table 1, The ANOVA reports an $F$ of .000 , which with 1 and 88 degrees of freedom is not statistically significant $(\mathrm{P}>0.05)$. The high $\mathrm{P}$ value in Table 3 indicates that we accept the "Null Hypothesis" of no difference between the two groups of students in the transparency judgment task.

TABLE 4

ANALYSIS OF VARIANCE (IDIOM COMPREHENSION TASK) SCORE (OUT OF 20)

\begin{tabular}{|c|c|c|c|c|c|}
\hline & & $\mathrm{JF} 2$ & & & \\
\hline & Sum of Squares & df & Mean Square & $\mathrm{F}$ & Sig. \\
\hline $\begin{array}{l}\text { Between Groups } \\
\text { Within Groups } \\
\text { Total }\end{array}$ & $\begin{array}{l}1088.544 \\
768.356 \\
1856.900\end{array}$ & $\begin{array}{l}1 \\
88 \\
89\end{array}$ & $\begin{array}{l}1088.544 \\
8.731\end{array}$ & 124.671 & .000 \\
\hline
\end{tabular}

With $F(1,88)=2.890, \mathrm{P}=0.000(\mathrm{P}<0.05)$. Therefore, we can comfortably reject the "Null Hypothesis" of no difference between the two groups of students for the idiom comprehension task. Based on Table 4 above, $\mathrm{E}^{2}$ is 0.58 indicating that the students' level ( 1 or 4 ) explains about 58 percent of the variation in number of idioms comprehended. We could say that this relationship is strong. 
TABLE 5

LIST OF IDIOMS WITH MEAN FAMILIARITY, TRANSPARENCY, AND COMPREHENSION RATINGS AND SCORES, BY COURSE LEVEL

\begin{tabular}{|c|c|c|c|c|c|c|c|}
\hline & & \multicolumn{2}{|l|}{ Familiarity } & \multicolumn{2}{|c|}{ Transparency } & \multicolumn{2}{|c|}{ Comprehension } \\
\hline & & Level 1 & Level 4 & Level 1 & Level 4 & Level 1 & Level 4 \\
\hline 1 & Go by the book & 3.31 & 3.57 & 2.51 & 2.31 & 0.48 & 0.88 \\
\hline 2 & Go against the grain & 4.53 & 4.48 & 2.55 & 2.08 & 0.33 & 0.48 \\
\hline 3 & Turn the other cheek & 4 & 4.17 & 2.37 & 2.44 & 0.15 & 0.73 \\
\hline 4 & Put one's foot down & 3.84 & 3.84 & 2.4 & 2.42 & 0.24 & 0.73 \\
\hline 5 & Skate on thin ice & 4.53 & 4.57 & 2.33 & 2.28 & 0.35 & 0.64 \\
\hline 6 & Bring the house down & 4.02 & 3.53 & 2.66 & 2.73 & 0.37 & 0.6 \\
\hline 7 & Put their heads together & 4 & 3.17 & 2 & 2.02 & 0.37 & 0.48 \\
\hline 8 & Read between the lines & 2.48 & 1.6 & 1.8 & 1.82 & 0.44 & 0.86 \\
\hline 9 & Cross swords with someone & 3.4 & 4.24 & 2.42 & 2.28 & 0.31 & 0.62 \\
\hline 10 & Keep your shirt on & 3.83 & 3.55 & 2.53 & 2.68 & 0.31 & 0.73 \\
\hline 11 & Give me a hand & 3.11 & 1.68 & 1.82 & 1.82 & 0.71 & 0.97 \\
\hline 12 & Beat around the bush & 4.53 & 4.15 & 2.53 & 2.75 & 0.26 & 0.17 \\
\hline 13 & Keep an eye on & 3.66 & 1.97 & 2.06 & 1.35 & 0.13 & 0.57 \\
\hline 14 & Let your hair down & 4.2 & 4.06 & 2.42 & 2.6 & 0.31 & 0.64 \\
\hline 15 & Make yourself at home & 3.15 & 2.48 & 1.75 & 1.95 & 0.42 & 0.95 \\
\hline 16 & Paper over the cracks & 4.55 & 4.62 & 2.66 & 2.73 & 0.2 & 0.24 \\
\hline 17 & Take someone under your wing & 4.51 & 3.57 & 1.84 & 1.88 & 0.37 & 0.84 \\
\hline 18 & Talk through one's hat & 4.55 & 4.48 & 2.17 & 2.53 & 0.35 & 0.73 \\
\hline 19 & Keep your nose clean & 3.73 & 3.46 & 2.46 & 2.64 & 0.33 & 0.93 \\
\hline 20 & Paint the town red & 4.73 & 4.42 & 2.75 & 2.55 & 0.31 & 0.93 \\
\hline M & & 3.93 & 3.58 & 2.30 & 2.29 & 0.33 & 0.68 \\
\hline SD & & 0.61 & 0.95 & 0.31 & 0.38 & 0.12 & 0.22 \\
\hline Rai & & $2.48-4.73$ & $1.68-4.62$ & $1.8-2.75$ & $1.35-2.75$ & $0.13-0.71$ & $0.17-0.97$ \\
\hline
\end{tabular}

Table 5 shows a list of the 20 idioms with their familiarity and transparency ratings, and the comprehension scores for both student groups. Level 1 students had a mean of 3.93 for familiarity and 2.30 for transparency, whereas Level 4 students scored 3.58 and 2.29 for familiarity and transparency ratings, respectively. Since low numbers reflect greater familiarity and transparency, these mean scores represents moderate familiarity and transparency levels for both groups. The table also indicates that Level 4 students comprehended idioms better than Level 1 students did.

In order to examine the association between familiarity, transparency, and comprehension, the five easiest and the five most difficult idioms were identified for each group according to the results of the comprehension task. The easiest idioms for Level 1 students were Go by the book, Bring the house down, Read between the lines, Give me a hand, and Make yourself at home. The most difficult expressions were Turn the other cheek, Put one's foot down, Beat around the bush, Keep an eye on, and Paper over the cracks. The easiest idioms for Level 4 students were Go by the book, Give me a hand, Make yourself at home, Keep your nose clean, and Paint the town red. The most difficult ones were Go against the grain, Put their heads together, Beat around the bush, Keep an eye on, and Paper over the cracks.

For each participant, a raw score was assigned indicating the total number of comprehended expressions $(1 \times 5=5$ possible per set), the total points given for rating idiom familiarity $(5 \times 5=25$ possible per set $)$, and the total points given for rating idiom transparency $(3 \times 5=15$ possible per set). Table 6 displays these results.

TABLE 6

MEAN FAMILIARITY, TRANSPARENCY, AND COMPREHENSION RATINGS AND SCORES FOR THE FIVE EASIEST AND FIVE MOST DIFFICULT IDIOMS, BY LEVEL

\begin{tabular}{|c|c|c|c|c|c|c|}
\hline & \multicolumn{2}{|c|}{ Familiarity } & \multicolumn{2}{|c|}{ Transparency } & \multicolumn{2}{|c|}{ Comprehension } \\
\hline & Easiest & Most Difficult & Easiest & Most Difficult & Easiest & Most Difficult \\
\hline \multicolumn{7}{|l|}{ Level 1} \\
\hline Mean & 15.91 & 20.68 & 10.62 & 12.13 & 2.42 & 1.00 \\
\hline S. D. & 4.47 & 3.31 & 1.93 & 1.84 & 1.27 & 1.06 \\
\hline Range & $9-25$ & $13-25$ & $6-15$ & $8-15$ & $0-5$ & $0-3$ \\
\hline \multicolumn{7}{|l|}{ Level 4} \\
\hline Mean & 15.58 & 18.42 & 11.33 & 10.96 & 4.64 & 2.00 \\
\hline S. D. & 4.50 & 3.57 & 2.50 & 1.71 & 0.64 & 1.18 \\
\hline Range & $6-25$ & $8-25$ & $5-14$ & $7-14$ & $2-5$ & $0-5$ \\
\hline
\end{tabular}

T-tests show that for Level 1 students, the easiest idioms were significantly more familiar $(\mathrm{t}=-7.969, \mathrm{p}<.000)$ and transparent $(\mathrm{t}=-4.460, \mathrm{p}<.000)$ than the most difficult ones. For Level 4 students, the easiest idioms were also significantly more familiar $(\mathrm{t}=-4.737, \mathrm{p}<.000)$ than the most difficult ones. However, the two sets of idioms did not differ for transparency ratings by these Level 4 students $(t=1.272, \mathrm{p}>.05)$.

\section{DISCUSSION}

This study was designed to investigate the difference between Level 1 and Level 4 EFL students asked to judge the familiarity and transparency of 20 English idioms. The subjects' ability to comprehend the 20 idioms they rated for 
familiarity and transparency was also examined. Results showed that Level 1 students were less familiar and had more difficulty with comprehension of idioms than Level 4 students. However, all subjects, regardless of their level, did not differ in their ability to rate transparency.

The finding that Level 4 students showed greater familiarity is expected, given the fact that their age, level of literacy, and amount of education are higher compared to the Level 1 students. This result is not surprising; it is consistent with prior research where similar results were found for the same reasons (Nippold \& Martin, 1989; Nippold \& Rudzinski, 1993). Level 4 students have been engaged in more tasks requiring reading and inferring meanings of words and expressions.

Although Level 1 students showed less familiarity with idioms than Level 4 students did, in both levels students rated the idioms as less familiar than expected. The high numbers in the familiarity task indicate lower familiarity. It shows that students' exposure to idiom expressions is insufficient. Since they are all EFL students, and like most second/foreign language learners, they focus first on the literal meanings of words while building a basic knowledge of vocabulary. They have less opportunity to focus on idioms. This issue must be taken into consideration by EFL course designers and teachers. Course designers need to present idioms intensively as ESL/EFL students need greater amount of exposure to non-literal language. Teachers might consider using readings to introduce new idioms. Teachers might also think about using classroom activities to practice these expressions and train learners to use idioms in their spoken and written English.

The first-level students' transparency judgments did not differ from those of the fourth-level second Language students. For the first-level students, the easiest idioms were also more familiar and transparent than the most difficult expressions. For the fourth-level Learners, the easiest idioms were more familiar than the most difficult ones, but the two types did not differ in transparency. This result indicates that all subjects approach the task similarly and suggests that transparency, unlike familiarity which shows age-related changes, is a fixed property of idioms (Nippold \&Taylor, 2002). This result is not unexpected as the differences between transparent and opaque idioms are less apparent with a forced choice task (Gibbs, 1987). It indicates that both groups of students have almost the same knowledge of idioms. Since their knowledge of idioms is similar, there seems to be little likelihood for students of their group to infer the nonliteral meaning from the literal meaning of certain expressions (Nippold \& Rudzinski, 1993). Therefore, they are less likely to observe transparency. It seems that all students are in an early stage of the process of acquiring idiom interpretation. Their incomplete knowledge of the non-literal meanings of idioms led to higher ratings (lower accuracy) in idiom transparency.

As predicted, Level 4 students outperformed Level 1 students in the idiom comprehension task. The lowest number of comprehended idioms by Level 4 students was 6, contrasted with a low of 2 for total idioms comprehended by Level 1 students. The maximum number of comprehended idioms by Level 4 students was 19, with up to 16 idioms comprehended by Level 1 students. This result was expected, since Level 4 students have three more years of exposure to the English language and have developed more strategies to handle such tasks. Therefore, exposure to vocabulary in context through reading yielded greater comprehension accuracy.

After identifying the five easiest and most difficult idioms for each group, it appears that the easiest idioms for Level 1 students were significantly more familiar and transparent than the most difficult ones. For Level 4 students, the easiest idioms were more familiar than the most difficult ones. This result confirms that familiarity and transparency are important indicators of idiom comprehension. They provide further support for the two hypotheses mentioned earlier: "language experience" and the "metasemantic hypothesis".

\section{CONCLUSION}

The current study takes a further step toward studying judgments of idiom familiarity and transparency. The aim of this research was to examine how ESL/EFL students rate idiom familiarity, transparency, and comprehension. Data were collected from 90 participants studying in the English Language Department, Umm Al-Qura University. Participants were enrolled in two levels of English Grammar; first and fourth. Three tasks were administered in the following order: a Familiarity Judgment Task, an Idiom Comprehension Task, and a Transparency Judgment Task. Results showed that the Level 4 students rated the idioms higher in familiarity and comprehended them with greater accuracy than Level 1 students did. However, students in the two groups performed similarly on the idiom transparency task. To further examine the association between familiarity, transparency, and comprehension, the five easiest and the five most difficult idioms were identified for each group. Results showed that for Level 1 students, the easiest idioms were significantly more familiar and transparent than the most difficult ones. For Level 4 students, the easiest idioms were significantly more familiar than the most difficult ones, but the two sets of idioms did not differ in transparency. This evidence appears to support the "language experience hypothesis" and the "metasemantic hypothesis".

The findings in this study suggest a number of implications that need to be taken into consideration. Teachers have to provide students with more assignments and exercises that involve inferring idiom meanings and using these expressions in meaningful contexts. Future research investigating idiom familiarity and transparency of Saudi students will need to address questions about transparency and the factors affecting students' transparency ratings. Since this study was conducted on male learners only, further research might be conducted on female Saudi learners as well. It is difficult to determine the degree to which the brief context and alternatives provided in this multiple choice task 
affected comprehension. Further research is needed to examine their impact, since the effects of methodological choices like these on results cannot be overestimated. Moreover, further study is needed to examine the effects of student' background and involvement with the language on idiom comprehension.

\section{REFERENCES}

[1] Ackerman, B. P. (1982). On comprehending idioms: Do children get the picture? Journal of Experimental Child Psychology, 33, 439-454.

[2] Arnaud, P. J. L. \& Savignon, S.J. (1997). Rare words, complex lexical units and the advanced learner. In J. Coady \& T. Huckin (Eds.) Second Language Vocabulary Acquisition: a Rationale for Pedagogy. Cambridge: Cambridge University Press

[3] Brasseur, J., \& Jimenez, B. C. (1989). Performance of university students on the Fullerton Subtest of Idioms. Journal of Communication Disorders, 22, 351-359.

[4] Cacciari, C., \& Levorato, M. C. (1989). How children understand idioms in discourse. Journal of Child Language, 16, $387-405$.

[5] Gibbs, R. W. (1987). Linguistic factors in children's understanding of idioms. Journal of Child Language, 14, 569-586.

[6] Gibbs, R. W. (1991). Semantic analyzability in Children's understanding of idioms. Journal of Speech and Hearing Research, 34, 613-620.

[7] Irujo,S. (1986a). Don't Put Your Leg in Your Mouth: Transfer in the Acquisition of Idioms in a Second Language. TESOL Quarterly 20 (2), 287-304

[8] Irujo, S. (1986b). A piece of cake: learning and teaching idioms. ELT Journal 40 (3), 236-242.

[9] Kellerman, E. (1977). Towards a characterization of the strategy of transfer in second language learning. Interlanguage Studies Bulletin 2, 58-145

[10] Kainulainen, T. (2006). Understanding Idioms: A comparison of Finnish third grade students of national senior secondary school and IB Diploma Programme. University of Jyväskylä. Retrieved (May, 17, 2010) from https://jyx.jyu.fi/dspace/bitstream/handle/123456789/7326/URN_NBN_fi_jyu-200679.pdf?sequence=1

[11] Lavel, V. (2003). Idiom comprehension and metapragmatic knowledge in French children. Journal of Pragmatics 35, $723-739$.

[12] Lazar, R. T., Warr-Leeper, G. A., Nicholson, C. B., \& Johnson, S. (1989). Elementary school teachers' use of multiple meaning expressions. Language, Speech, and Hearing Services in Schools, 20, 420-430.

[13] Levorato, M. C., \& Cacciari, C. (1992). Children's comprehension and production of idioms: The role of context and familiarity. Journal of Child Language, 19, 415-433.

[14] Levorato, M. C., \& Cacciari, C. (1995). The effects of different tasks on the comprehension and production of idioms in children. Journal of Experimental Child Psychology, 60, 261-283.

[15] Mäntylä, K. (2004). Idioms and language users: the effect of the characteristics of idioms on their recognition and interpretation by native and non-native speakers of English [online]. University of Jyväskylä. Retrieved (May 31, 2005) from: http://selene.lib.jyu.fi:8080/vaitos/studies/studhum/9513917177.pdf.

[16] Marinellie, S. \& Chan, Y, L. (2008). Definitions of Idioms in Preadolescents Adolescents, and Adults. Journal of Psycholinguistic Research, 37 (1), 1-20.

[17] Nippold, M. A. (1991). Evaluating and enhancing idiom comprehension in language-disordered students. Language, Speech, and Hearing Services in Schools, 22, 100-106.

[18] Nippold, M. A., Moran, C., \& Schwarz, I. E. (2001).Idiom understanding in pre-adolescents: Synergy in action. American Journal of Speech-Language Pathology, 10, 169-179.

[19] Nippold, M. A., \& Duthie, J. K. (2003). Mental imagery and idiom comprehension: A comparison of school-age children and adults. Journal of Speech and Hearing Research, 46, 788-799.

[20] Nippold, M. A., \& Rudzinski, M. (1993). Familiarity and transparency in idiom explanation: A developmental study of children and adolescents. Journal of Speech and Hearing Research, 36, 728-737.

[21] Nippold, M. A., \& Taylor, C. L. (1995). Idiom understanding in youth: Further examination of familiarity and transparency. Journal of Speech and Hearing Research, 38, 426-433.

[22] Nippold, M. A., \& Martin, S. T. (1989). Idiom interpretation in isolation versus context: A developmental study with adolescents. Journal of Speech and Hearing Research, 32, 59-66.

[23] Nippold, M. A., Taylor, C. L., \& Baker, J. M. (1996). Idiom understanding in Australian youth: A cross-cultural comparison. Journal of Speech and Hearing Research, 39, 442-447.

[24] Ortony, A., Turner, T. J., \& Larson-Shapiro, N. (1985). Cultural and instructional influences on figurative language comprehension by inner city children. Research in the Teaching of English, 19, 25-36.

[25] Prinz, P. M. (1983). The development of idiomatic meaning in children. Language and Speech, 26, 263-272.

[26] Qualls, C. D., \& Harris, J. L. (1999). Effects of familiarity on idiom comprehension in African American and European American fifth graders. Language, Speech, and Hearing Services in Schools, 30, 141-151.

[27] Qualls, C. D., O’Brien, R. M., Blood, G. W., \& Hammer, C. S. (2003). Contextual variation, familiarity, academic literacy and rural adolescents' idiom knowledge. Language, Speech, and Hearing Services in the Schools, 34, 69-79.

Sameer S. Aljabri was born in Jeddah, Saudi Arabia on April 25, 1975. He earned his MA in Theoretical Linguistics from Georgetown University, Washington D. C, USA in 2003, and a Ph.D. in Applied Linguistics (TESOL) from Indiana University of Pennsylvania, USA, in 2005.

Dr. Aljabri is currently an associate professor at the Department of English, Umm Al-Qura University, Makkah, Saudi Arabia. 